\title{
Impairment of ocular surface epithelium barrier function in patients with atopic dermatitis
}

\author{
Keiko Yokoi, Norihiko Yokoi, Shigeru Kinoshita
}

\begin{abstract}
Aims-To assess the integrity of the ocular surface epithelium in patients with atopic dermatitis from the viewpoint of its barrier function.

Methods-49 patients with atopic dermatitis with blepharoconjunctivitis (ABC group), 27 age matched patients with seasonal or perennial allergic conjunctivitis (AC group), and 20 volunteers with normal healthy eyes (NH group) were assigned to this study. Ocular surface epithelium barrier function was evaluated by the fluorophotometric method using a slit lamp fluorophotometer. $3 \mu 1$ of $0.5 \%$ sodium fluorescein was instilled into the conjunctival sac of the right eye and fluorescein uptake (ng/ml) $\mathbf{3 0}$ minutes later (20 minutes after eye washing) was measured in the central cornea and the temporal bulbar conjunctiva. Fluorophoto metric measurements performed were analysed in each group and compared between the groups.
\end{abstract}

Results-The ABC group showed significantly higher fluorescein uptake (mean 28.2 (SEM 3.3) $\mathrm{ng} / \mathrm{ml}$ ) in the cornea than the AC (11.4 (2.2), p=0.001) and NH groups $(9.3(2.1), p=0.001)$. There was no significant difference between the $A C$ and NH groups $(p=0.930)$. The ABC group also showed significantly higher fluorescein uptake in the bulbar conjunctiva (393.4 (54.0)) than the AC (182.9 (24.6), $\mathrm{p}=0.011)$ and NH groups (169.3 (29.1), $\mathrm{p}=0.012)$. There was also no significant difference in fluorescein uptake between the AC group and the NH group $(p=0.987)$.

Conclusion-This study suggested that ocular surface epithelium barrier function is impaired in patients with atopic dermatitis with blepharoconjunctivitis.

Department of

Ophthalmology, Kyoto Prefectural University of Medicine, Kyoto,

Japan

K Yokoi

N Yokoi

S Kinoshita

Correspondence to:

Keiko Yokoi, MD,

Department of

Ophthalmology, Kyoto

Prefectural University of

Medicine, 465 Kajii-cho,

Hirokoji-agaru,

Kawaramachi-dori,

Kamigyo-ku, Kyoto 602,

Japan.

Accepted for publication 17 February 1998 punctate epithelial keratitis, macroerosion, and plaques similar to that seen in VKC. Also, there have been rare reports of conjunctival epithelial abnormalities in AKC, ${ }^{9}$ even though the clinical manifestations of conjunctivitis in this condition are well known. Regarding the mechanism of corneal involvement in AKC, recent studies have demonstrated that allergy associated substances such as eosinophil granule major basic protein (MBP) and eosinophil cationic protein (ECP) are possibly influential. ${ }^{10} 11$ These substances have been demonstrated in the tears of AKC patients, ${ }^{12}$ and have a cytotoxic effect on corneal epithelial cells in vitro. ${ }^{13} 14$

There is also a subgroup of patients with atopic dermatitis with chronic allergic conjunctivitis which do not show keratopathy; this variant is sometimes termed atopic blepharoconjunctivitis (ABC).$^{78} \mathrm{~A}$ previous histopathological study of AKC and ABC has suggested that the difference between these disorders is chiefly a matter of degree ${ }^{8}$ and that the corneal epithelium might be expected to be involved in $\mathrm{ABC}$ as well as AKC. However, as the proposed epithelial changes in ABC are subtle, they are difficult to detect using slit lamp biomicroscopy.

In the present study, we examined the subclinical change in the corneal and conjunctival epithelia in patients with atopic dermatitis with $\mathrm{ABC}$ by measuring epithelial barrier function using fluorophotometry as a sensitive method. ${ }^{15-17}$ Then we compared the results with those from seasonal or perennial conjunctivitis patients, and normal healthy eyes.

\section{Subjects and methods}

PATIENTS AND HEALTHY VOLUNTEERS

Following fully informed consent, 49 atopic dermatitis patients with atopic blepharoconjunctivitis (ABC group) (aged 9-36 years (mean 21.5 (SD 5.6) years), 28 males, 21 females), 27 age matched seasonal or perennial allergic conjunctivitis patients (AC group) (aged 12-46 years (23.3 (7.2) years), seven males, 20 females), and 20 volunteers with normal healthy eyes (NH group) (aged 12-36 years (21.7 (5.9) years), nine male, 11 females) were assigned to this study. The diagnostic criterion for atopic blepharoconjunctivitis was mild chronic conjunctivitis in atopic dermatitis without keratopathy, which was confirmed by slit lamp biomicroscopy. Atopic dermatitis was diagnosed by a dermatologist in a special clinic for atopic dermatitis, in accordance with previously reported diagnostic criteria. ${ }^{18}$ The diagnostic criteria for seasonal or perennial conjunctivitis included mild papillary conjunctivitis with itching or other complaints, positive findings on the radioallergosolvent test, no identifiable cause of ocular inflammation other than 
allergy, and no atopic dermatitis. Cases with apparent chemosis and prominent lacrimation, which could interfere with the fluorophotometry, were excluded. Normal volunteers had no abnormalities of the cornea, conjunctiva, or meibomian glands by observation with slit lamp biomicroscopy, no lacrimal passage problems, and no history of allergic conjunctivitis, dry eye, or contact lens wearing.

\section{CHARACTERISTICS OF SLIT LAMP}

FLUOROPHOTOMETER

In this study a slit lamp fluorophotometer (FL-500, Kowa Co, Japan) was used to measure epithelial barrier function. ${ }^{15-17}$ The measurement area was small $(0.15 \mathrm{~mm} \times 0.3$ $\mathrm{mm}$; vertical $\times$ horizontal section) and the longitudinal length of the focal diamond was 0.66 $\mathrm{mm}$ and $0.33 \mathrm{~mm}$ from the corneal surface along the horizontal and vertical sections, respectively. The maximal plane of the focal diamond of the receiving system could be easily adjusted to the corneal surface while the observer viewed the cornea from the front, and the fluorescent light could be detected directly from the front. This approach to viewing could be applied not only at the central cornea, but also at the bulbar conjunctiva. A measurement angle of $30^{\circ}$, which represents the degrees of illumination system away from the receiving system in the horizontal plane, was selected and the measurement time was 0.2 second.

\section{MEASUREMENT OF EPITHELIAL BARRIER}

FUNCTION

Measurement of corneal epithelium barrier function was performed as described previously. ${ }^{15-17}$ With the instrument focused on the central cornea of the right eye, and subsequently focused on the temporal bulbar conjunctiva $3 \mathrm{~mm}$ away from the limbus at the 9 o'clock position, background fluorescence (autofluorescence) intensity was measured 10 times and averaged. In the adjustment of the maximal focal diamond plane onto the conjunctival surface, the other eye (left eye) was led to the left hand side, so that the measurement area faced directly to the front, using the fixation light attached to the fluorophotometer. This method was useful for expanding the conjunctival folding which was expected to cause variations in the target volume during the fluorophotometry. A reticle consisting of three concentric circles relative to the conjunctival vessels also helped in adjustment of the maximal focal diamond plane onto the conjunctival surface. After these measurements, $3 \mu \mathrm{l}$ of a $0.5 \%(5 \mathrm{mg} / \mathrm{ml})$ BSS Plus (Alcon, Fort Worth, TX, USA) fluorescein solution was instilled into the lower conjunctival sac of the right eye with an Eppendorf micropipette, in a non-contact fashion, followed by washing of the lower tarsal conjunctiva, conjunctival sac, bulbar conjunctiva, cornea, and upper tarsal conjunctiva with 20 $\mathrm{ml}$ of BSS Plus 10 minutes later. Twenty minutes after the eye was washed, fluorescence intensity was measured 10 times in the same portion of the central cornea and temporal bulbar conjunctiva where the autofluorescence

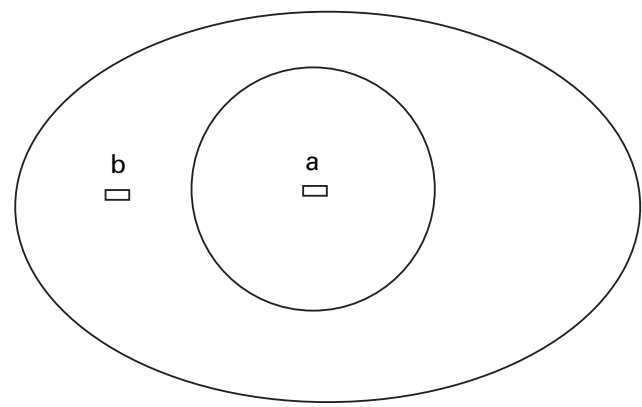

Figure 1 A schema indicating the site of fluorophotometric measurement. Fluorescein uptake was measured in the central cornea (a) and temporal bulbar conjunctiva $3 \mathrm{~mm}$ away from the limbus (b). The measurement area was $0.15 \mathrm{~mm} \times 0.3 \mathrm{~mm}$ (vertical $\times$ horizontal section)

was measured and the data were averaged. Autofluorescence of the conjunctiva was higher than that of cornea, so that maximum care was taken so as to measure the identical conjunctival portion that was evaluated in the autofluorescence measurement. The mean value of autofluorescence was then subtracted; the counts obtained were converted into fluorescein concentrations using calibration lines incorporated in the software. From this concentration, corneal and conjunctival epithelium barrier function was evaluated. The reproducibility and reliability for evaluating barrier function is reportedly quite satisfactory, as described elsewhere. ${ }^{15} 17$ The region used for measurement is shown schematically in Figure 1.

After the fluorophotometry, with the aid of fluorescein filter paper, it was confirmed that the portion of the central cornea and bulbar conjunctiva subjected to fluorophotometry was free from any fluorescein detectable punctate epithelial lesions or epithelial defects.

\section{STATISTICAL ANALYSIS}

The results were expressed as means (SEM). The fluorescein uptake values obtained for each group were compared using the KruskalWallis test and Scheffe's test. A p value of 0.05 or less was considered to be significant.

\section{Results}

COMPARISON OF CORNEAL FLUORESCEIN UPTAKE BETWEEN ABC, AC, AND NH GROUPS

Corneal fluorescein uptake in the ABC, AC, and $\mathrm{NH}$ groups was 28.2 (3.3) $\mathrm{ng} / \mathrm{ml}$ (mean (SEM)), 11.4 (2.2), and 9.3 (2.1), respectively. A significant difference was noted in fluorescein uptake between the three groups (Kruskal-Wallis test, $\mathrm{p}<0.0001$ ), with markedly higher fluorescein uptake in the ABC group than in the AC or NH group (Scheffe's test, $p=0.001$ and $p=0.001$, respectively). There was no significant difference between the AC and NH group (Scheffe's test, $\mathrm{p}=0.930)($ Fig 2$)$.

COMPARISON OF CONJUNCTIVAL FLUORESCEIN UPTAKE BETWEEN ABC, SEASONAL OR PERENNIAL CONJUNCTIVITIS, AND NORMAL GROUPS Conjunctival fluorescein uptake in the $\mathrm{ABC}$, $\mathrm{AC}$, and $\mathrm{NH}$ groups was 393.4 (54.0) $\mathrm{ng} / \mathrm{ml}$ (mean (SEM)), 182.9 (24.6), and 169.3 


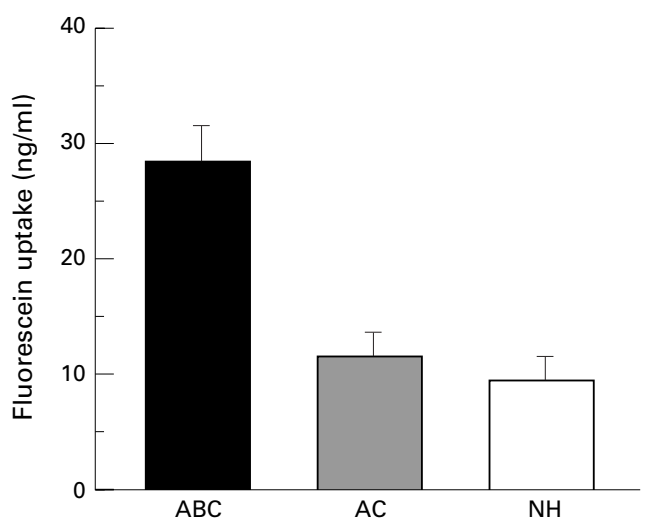

Figure 2 Comparison of corneal fluorescein uptake between atopic dermatitis patients with atopic

blepharoconjunctivitis $(A B C)$, seasonal or perennial allergic conjunctivitis patients ( $A C)$, and volunteers with normal healthy eyes (NH). A significant difference was noted in fluorescein uptake between the three groups $(p<0.0001)$, with markedly higher fluorescein uptake in the $A B C$ than in the $A C$ or NH groups ( $p=0.001$ and $p=0.001$, respectively). There was no significant difference between the $A C$ and NH groups ( $p=0.930)$.

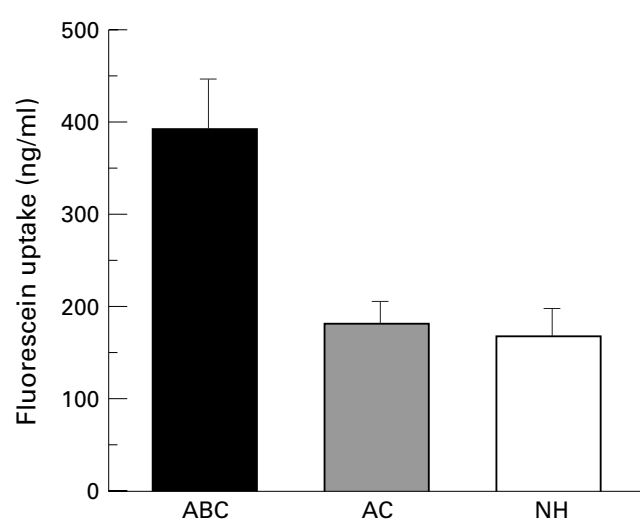

Figure 3 Comparison of conjunctival fluorescein uptake between atopic dermatitis patients with atopic

blepharoconjunctivitis $(A B C)$, seasonal or perennial allergic conjunctivitis patients $(A C)$, and volunteers with normal healthy eyes (NH). A significant difference was noted in the fluorescein uptake between the three groups $(p=0.0003)$, with markedly higher fluorescein uptake in the $A B C$ than in the $A C$ or NH group ( $p=0.011$ and $p=0.012$, respectively). There was no significant difference between the $A C$ and NH group $(p=0.987)$.

(29.1), respectively. A significant difference was noted in fluorescein uptake between the three groups (Kruskal-Wallis test, $\mathrm{p}=0.0003$ ), with markedly higher fluorescein uptake in the ABC than in the AC or NH group (Scheffe's test, $\mathrm{p}=0.011$ and $\mathrm{p}=0.012$, respectively). There was no significant difference between the AC and NH group (Scheffe's test, $\mathrm{p}=0.987)($ Fig 3$)$.

\section{Discussion}

Barrier function is one of the important functions of the ocular surface epithelium and is maintained by intact tight junctions and cell membrane structure of the superficial epithelial cells. Therefore, information regarding barrier function reflects the integrity of the ocular surface epithelium. This study applied fluorophotometry to evaluate ocular surface epithelium barrier function in atopic dermatitis patients with atopic blepharoconjunctivitis by measuring fluorescein uptake, and the results were compared with those in seasonal and perennial conjunctivitis and normal healthy eyes.

The present study demonstrated that fluorescein uptake by the cornea and conjunctiva in the $\mathrm{ABC}$ group was significantly higher than that in the other groups. This observation indicates that corneal epithelial barrier function is impaired in the ABC group and that this impairment is possibly related to a subclinical level of disruption in cell junctions or the cell membrane structure between the corneal surface epithelial cells. Our data also suggest that a similar event occurs in the conjunctival epithelium in ABC. However, several factors require careful consideration in the interpretation of conjunctival fluorescein uptake. One such factor is the variability in individual conjunctival thickness, which may introduce variations in the target volume (area for fluorophotometry) depending on the thickness. Conjunctival thickness is likely different between the groups and it is possible that conjunctival thickness in the ABC group was greater than that in the other groups. However, cases with apparent conjunctival oedema (chemosis) were not enrolled in the present study, and there were no cases with apparent conjunctival thickening as seen in the limbal form of vernal keratoconjunctivitis. Also, the conjunctiva subjected to the fluorophotometry is in an expanded condition; the expected conjunctival folds were presumably minimal. Moreover, the observation that there were 10 out of 49 ABC cases (20.4\%) with fluorescein uptake three times greater than that of the normal average cannot be explained on the basis of conjunctival thickness alone. Another factor which contributes to differences in fluorescein uptake by the ocular surface epithelium (cornea and conjunctiva) was reflex tearing in the examined groups. Reflex tears (lacrimation), however, even if they were present, cannot increase fluorescein uptake, and would instead be expected to have a dilutional effect on the applied fluorescein. Thus, it is safe to say that there is significant impairment of the entire ocular surface barrier function in the $\mathrm{ABC}$ group.

The aetiology of keratopathy in AKC is not known. However, recent studies have demonstrated the presence of eosinophil derived cytotoxic proteins, such as MBP or ECP, in human tears, ${ }^{112}$ corneal ulcerative lesions ${ }^{19}$ and the conjunctiva ${ }^{1020}$ in eyes with VKC or AKC. Moreover, these proteins have been demonstrated to have potential cytotoxic effects on the corneal epithelial cells in vitro. ${ }^{13} 14$ Based on these reports, the results of the present study may indirectly demonstrate the disruption of the ocular surface epithelium by esosinophil derived cytotoxic proteins in ABC, the mildest form of AKC.

In seasonal and perennial allergic conjunctivitis, on the other hand, judging from the comparison of the results between the AC and $\mathrm{NH}$ groups, there seemed to be no change in ocular surface epithelial permeability in AC group. However, in this group, there are some mechanisms which might alter the ocular 
surface epithelial permeability. Among them, histamine is a potential candidate, because this is the predominant chemical mediator in type I allergy (AC group) and has been known to increase vascular permeability. ${ }^{21}$ To make the effect of histamine on the barrier function of the ocular surface epithelium clearer, we examined the barrier function of ocular surface epithelium in a limited number of cases of histamine induced conjunctivitis in six healthy volunteers. Fluorophotometry was performed in an identical manner 10 minutes after instillation of $10 \mu \mathrm{l}$ histamine chloride solution $(1 \mathrm{mg} / \mathrm{ml})$. Since these results did not show any significant difference, histamine was thought to cause no permeability change in the ocular surface epithelium, contributing only to allergic ocular manifestations.

In conclusion, the present study revealed subclinical ocular surface epithelial problems in atopic dermatitis patients with ABC. Further investigation of the relation between the concentration of cytotoxic substance, such as MBP or ECP, in tears and barrier disruption should, however, be performed.

Supported in part by a research grant 60191491 from the Japanese Ministry of Education, Culture and Science and research fund from Kyoto Foundation for the Promotion of Medical Science.

1 Buckley RJ. Atopic diseases of the cornea. In: Cavanagh HD, ed. The cornea: transactions of the world congress on the cornea III, New York: Raven Press, 1988:435-7.

2 Friedlaender MH. Conjunctivitis of allergic origin:clinical presentation and differential diagnosis. Surv Ophthalmo 1993;38:105-14

3 Abelson MB, Udell IJ, Allansmith MR, et al. Allergic and toxic reactions. In: Albert DM, Jakobiec FA, eds. Principles and practice of ophthalmology. Vol 1. Philadelphia: WB Saunders, 1994:77-100.

4 Hogan MJ. Atopic keratoconjunctivitis. Trans Am Ophthalmol Soc 1952;50:265-81.
5 Hogan MJ. Atopic keratoconjunctivitis. Am 7 Ophthalmol 1953;36:937-47.

6 Foster CS, Calonge FM. Atopic keratoconjunctivitis. Ophthalmology 1990;97:992-1000.

7 Tuft SJ, Kemeny DM, Dart JKG, et al. Cinical features of atopic keratoconjunctivitis. Ophthalmology 1991;98:150-8.

8 Bacon AS, Tuft SJ, Metz DM, et al. The origin of keratopathy in chronic allergic eye disease:a histopathological study. Eye 1993;Suppl:21-5.

9 Roat MI, Ohji M, Hunt LVE, et al. Conjunctival epithelial cell hypermitosis and goblet cell hyperplasia in atopic keratoconjunctivitis. Am f Ophthalmol 1993;116:456-63.

10 Porter DP, Trocme SD, Foster CS, et al. Conjunctival deposition of eosinophil major basic protein, neutrophil elastase, and mast cell tryptase in atopic kerato-conjunctivitis. Invest Ophthalmol Vis Sci 1993;34(Suppl):855.

11 Montan RG, van Hage-Hamstern M. Eosinophil cationic protein in tears in allergic conjunctivitis. Br $\mathcal{f}$ Ophthalmol 1996;80:556-60.

12 Udell IJ, Gleich GJ, Allansmith MR, et al. Eosinophil granule major basic protein and Charcot-Leiden crystal protein in human tears. Am f Ophthalmol 1981;92:824-8.

13 Trocme SD, Gleich GJ, Zieske JD. Eosinophil granule major basic protein inhibits corneal epithelial wound healing in vitro. Invest Ophthalmol Vis Sci 1994;35:3051-6.

14 Trocme SD, Hallberg CK, Gill KS, et al. Effects of eosinophil granule proteins on human corneal epithelial cell viability and morphology. Invest Ophthalmol Vis Sci cell viability an

15 Yokoi N, Kinoshita S, Akiyama K. A new slit-lamp fluorophotometer for the clinical evaluation of corneal epithelial barrier function. Nippon Ganka Gakkai Zasshi (Acta Soc Ophthalmol fpn) 1994;98:641-7.

16 Yokoi N, Kinoshita S. Clinical evaluation of corneal epithelial barrier function with the slit-lamp fluorophotometer. Cornea 1995;4:485-9.

17 Tanihara H, Yokoi N, Komuro A, et al. Prolonged impairment of peripheral corneal epithelium barrier function after successful trabeculectomy. Am $\mathcal{F}$ Ophthalmol 1997;123:487-93.

18 Hanifin JM, Rajka G. Diagnostic feature of atopic dermatitis. Acta Derm Venereol (Stockh) 1993;92(Suppl):44-7.

19 Trocme SD, Kephart GM, Bourne WM, et al. Eosinophil granule major basic protein deposition in corneal ulcers associated with vernal keratoconjunctivitis. Am f Ophthalmol 1993;115:640-3.

20 Trocme SD, Kephart GM, Allansmith MR, et al. Conjunctival deposition of eosinophil granule major basic protein in vernal keratoconjunctivitis and contact lens associated giant papillary conjunctivitis. Am f Ophthalmol 1989;108: 57-63.

21 Abelson MB, Schaefer K. Conjunctivitis of allergic origin: immunologic mechanisms and current approaches to therapy. Surv Ophthalmol 1993;38:115-32. 